\title{
The anatomy of the Berrettini branch: implications for endoscopic carpal tunnel release
}

\author{
Zlatko Kolic, M.D., Vladimir Micovic, M.D., Gordana Zamolo, Ph.D., Vesna Golubovic, M.D., \\ Ph.D., Miljenko Uravic, M.D., Ph.D., and Marin F. Stancic, M.D.
}

Division of Neurosurgery, Department of Surgery, University of Rijeka Medical School, Croatia

Hand dissections were performed in 100 fresh cadaver palms to determine the frequency with which superficial palmar communication between the median and ulnar nerves occurs and to what extent it might incur iatrogenic injury during endoscopic carpal tunnel release.

Superficial palmar communication between the median and ulnar nerves was present in $81 \%$ of the dissected hands. Superficial palmar communication, also known as the Berrettini branch, has been classified into four distinct types by Ferrari and Gilbert. Thirty hands were classified as Group 1 (communication in an oblique course from the ulnar to the median nerve), 16 hands were classified as Group 2 (communication parallel to the distal margin of the transverse carpal ligament), and 35 hands were classified as Group 3 (communication in an oblique course from the ulnar nerve to the third common digital nerve, originating below the distal margin of the transverse carpal ligament). No hand fit the Group 4 classification (atypical communication).

These findings led the authors to conclude that changing the course of an incision in the distal part of the carpal ligament radially from the ulnar side a few millimeters is strongly recommended. Sensory branch iatrogenic injury can be avoided by using this technical alteration, in light of the fact that superficial palmar communication between the median and ulnar nerves may be the more likely anatomical finding.

Key Words * carpal tunnel release * endoscopic surgery * iatrogenic injury * median nerve * ulnar nerve * Berrettini branch

Carpal tunnel syndrome is the most common compressive neuropathy and can be treated surgically by using open or endoscopic release.[1,7,10,11,18] Although the long-term surgical results of both techniques are the same, endoscopic carpal tunnel release (ECTR) has a perceived lower frequency of complications and a more rapid return to function for the patient.[1] The use of this technique, however, has been associated with injury of the superficial palmar communication between the median and ulnar nerves, resulting in painful neuroma formation and alteration of middle and ring finger sensibility.[1,6,15] Superficial palmar communication between the median and ulnar nerve has alternately been described in the literature as a normal finding, an anatomical variation, an anomalous branch, or has been totally ignored.[2,4,6,8,14,15,18,19,23]

The goal of this study was to determine the frequency with which superficial palmar communication, 
also known as the Berrettini branch, occurs and to what extent it may be subject to iatrogenic injury during ECTR.

\section{CLINICAL MATERIAL AND METHODS}

One hundred fresh cadaver hands were dissected at the Department of Pathology and Pathological Anatomy at the University of Rijeka Medical School, following the guidelines set in place by the Medical School Ethics Committee. The hands were obtained from 27 male and 23 female cadavers; the average age at death was 57 years (range 30-84 years). Cadaveric dissections were performed with the aid of operating loupes (X 2.5 magnification). An incision was made on the palmar surface of the distal third of the forearm extending to the distal transverse crease of the palm in the axis of the ring finger. The transverse carpal ligament (TCL) was opened longitudinally and Guyon's canal was unroofed, avoiding disturbance of its contents.[2,3,6,15,16,20,21] When a Berrettini branch was identified, the distance from the origin of the communicating nerve to the ulnar nerve and the distal margin of the TCL was measured in millimeters. The angle at which this communication forms with the ulnar nerve was measured in degrees.

The hands were classified into four groups according to the scheme of Ferrari and Gilbert.[6]

Group 1. Hands in which communication is directed obliquely from the ulnar to the median nerve and the distance between the origin of the communication and the distal end of the TCL is more than $4 \mathrm{~mm}$ and the angle does not exceed 54š (Fig. 1 left).

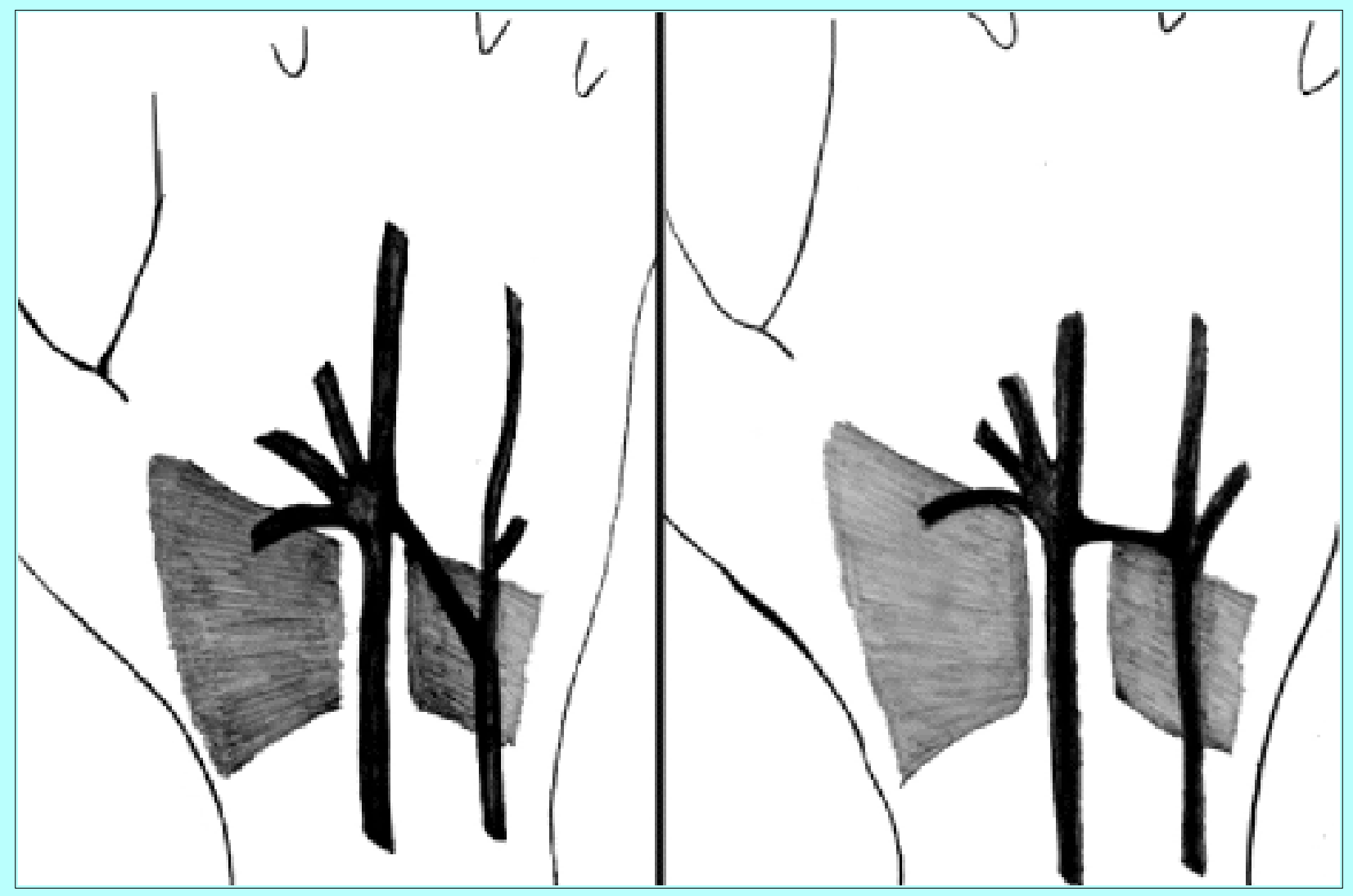

Fig. 1. Left: Schematic drawing illustrating a Group 1 communication. Right: Schematic drawing illustrating a Group 2 communication.

Group 2. Hands in which communication is directed parallel to the distal margin of the TCL. The distance is less than $4 \mathrm{~mm}$ from the origin to the distal margin of the TCL and at a right angle to the ulnar 
nerve (Fig. 1 right).

Group 3. Hands in which communication is directed obliquely from the ulnar nerve to the third common digital nerve, whose origins are below the distal margin of the TCL, and in which the angle is very acute (Fig. 2 left).

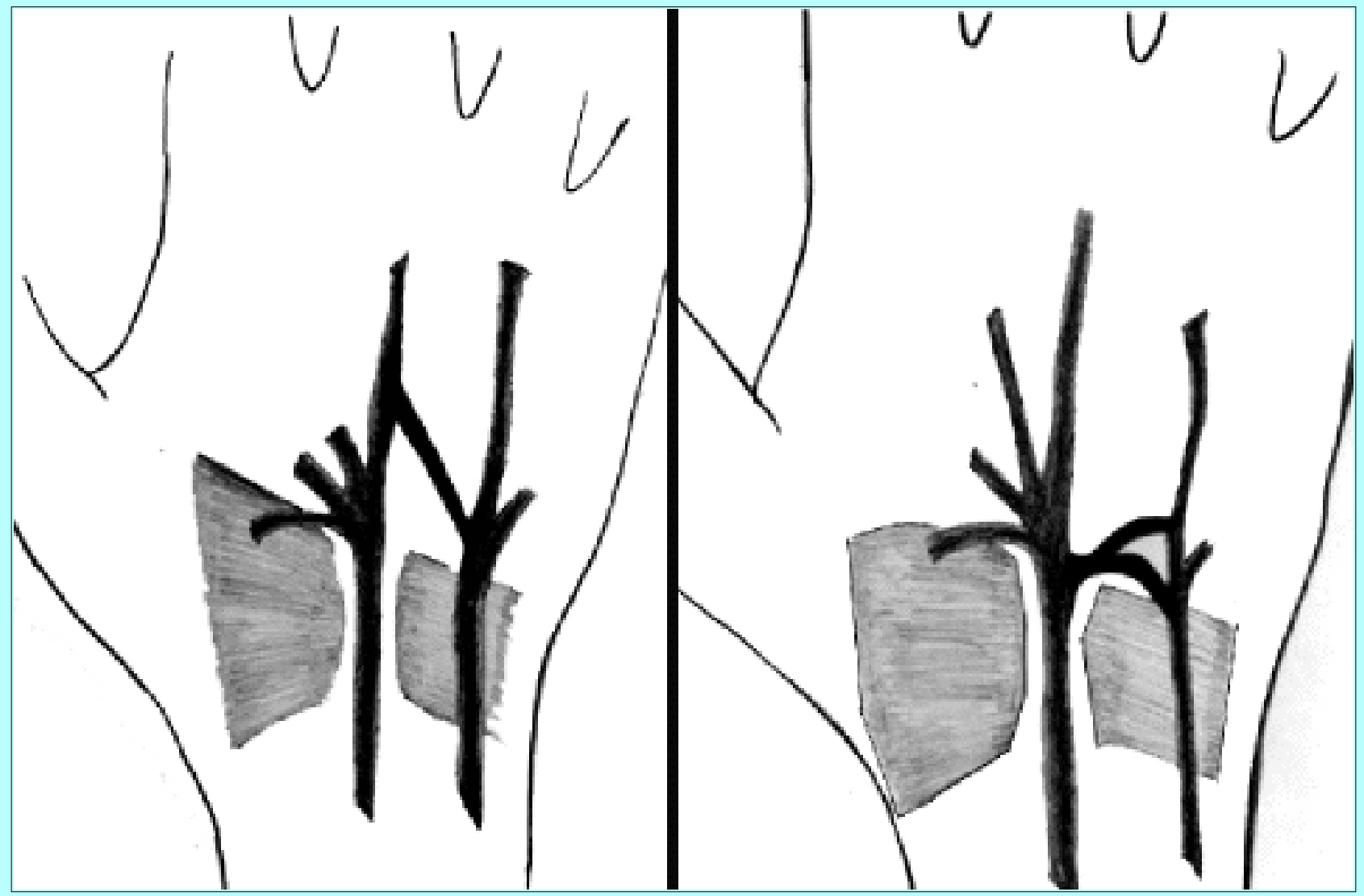

Fig. 2. Left: Schematic drawing illustrating a Group 3 communication. Right: Schematic drawing illustrating a Group 4 atypical communication.

Group 4. Hands in which an atypical communication is directed from the median to the ulnar nerve, occasionally with a double-communicating branch. (Fig. 2 right).

\section{RESULTS}

Superficial palmar communication between the median and ulnar nerves was present in $81(81 \%)$ of the 100 dissected palms. We found an approximately equal number of right hands (nine) and left hands (10) in which communication was not present.

Using the scheme of Ferrari and Gilbert,[6] 30 hands (37\%) were classified into Group 1. In those hands the communication passed through the TCL from the ulnar to the median nerve. The average distance between the origin and the distal margin of the TCL was $4.21 \mathrm{~mm}$, ranging from 2.5 to $5.5 \mathrm{~mm}$. The average angle at which the communication formed with the ulnar nerve was $495556^{\prime}$, ranging from 38 š to 60š. Right hands (18) were represented more often in Group 1 than left hands (12).

There were 16 hands classified as Group 2. In these hands the communication was parallel to the distal margin of the TCL. The average distance between the origin of communication and the distal margin of the TCL was $2.05 \mathrm{~mm}$, ranging from 1.5 to $3.5 \mathrm{~mm}$. The average angle at which the communication formed with the ulnar nerve was 86 š $^{6} 8^{\prime}$, ranging from 80š to 90 š. Left hands (10) were represented more 
often in Group 2 than right hands (6).

There were 35 hands classified as Group 3. In these hands the communication was directed obliquely from the ulnar nerve to the third common digital nerve, originating below the distal margin of the TCL. Both hands were represented equally in Group 3: 17 right hands and 18 left hands.

There were no hands that could be classified as Group 4 in this study.

\section{DISCUSSION}

The results of our study indicate that the Berrettini branch is a normal anatomical finding rather than a variation or an anomaly (Table 1). In our study the Berrettini branch presented in $81 \%$ cases, closely paralleling the findings of Meals and Shaner.[15] Some authors report an even higher incidence: 100\% in some studies, $[2,8,12,19]$ and $95 \%$ in others.[6] Anatomy textbooks do not mention the existence of this communication, whereas anatomy atlases illustrate it as r. communicans or r. anastomoticus.[21,23,24]

\begin{tabular}{|c|c|c|c|c|c|}
\hline \multicolumn{6}{|c|}{$\begin{array}{r}\text { TABLE } 1 \\
\text { FREQUENCY OF BERRETT NI BRANCH YAR LTTIONS I }\end{array}$} \\
\hline Yariatle & $\begin{array}{l}\text { WO Com- } \\
\text { murication }\end{array}$ & $\begin{array}{l}\text { Group } 1 \\
\text { (range) }\end{array}$ & $\begin{array}{l}\text { Group } 2 \\
\text { (range) }\end{array}$ & $\begin{array}{l}\text { Group } 3 \\
\text { (range) }\end{array}$ & Group 4 \\
\hline total no. of hands & 19 & 30 & 16 & 35 & 0 \\
\hline rthands & 9 & $\begin{array}{l}18 \\
12\end{array}$ & 6 & 17 & 0 \\
\hline $\begin{array}{l}\text { It hands } \\
\text { distance (mm)t }\end{array}$ & 10 & $4.21(2.5-5.5)$ & $2.05(105-3.0)$ & 18 & 0 \\
\hline angle (degrees)t† & - & $49^{\circ} 56^{\prime}\left(38^{\circ}-60^{\circ}\right)$ & $86^{\circ} 68^{\prime}\left(80^{\circ}-90^{\prime}\right)$ & - & - \\
\hline
\end{tabular}

\section{Origin of the Name}

The term Berrettini branch as used in this study (according to Pietro Berrettini de Cortona, painter, who illustrated this communication in the anatomical atlas of Gaetano Petrioli Romano (Fig. 3) in 1741[17]) was introduced into the medical literature by Meals and Calkins[14] in 1991. 


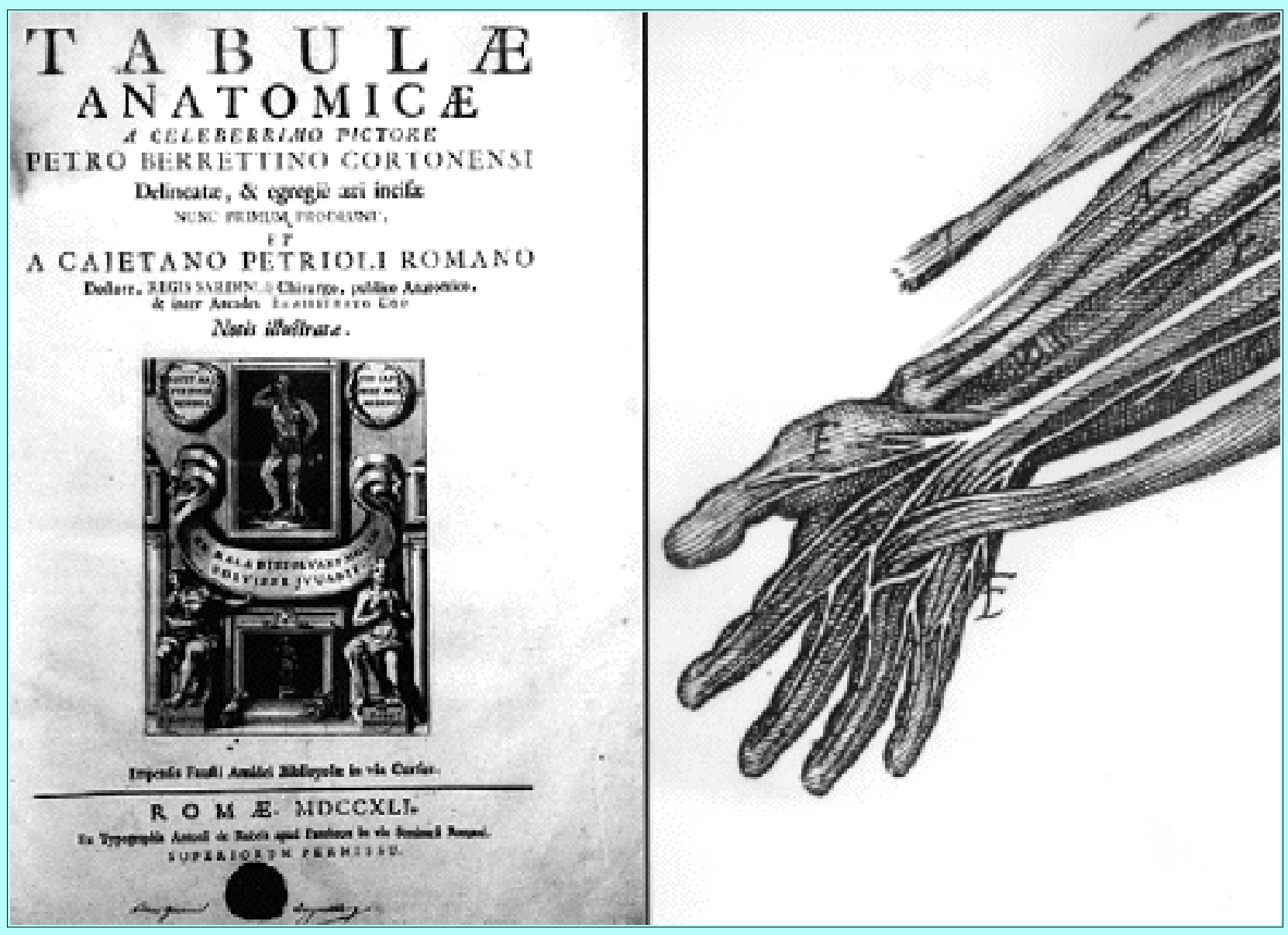

Fig. 3. Left: Reproduction of the front page of Tabulae Anatomicae, illustrated by Pietro Berrettini. Right: Reproduction of a figure from Tabulae Anatomicae showing superficial palmar communication as a normal anatomical finding.

\section{Classification System}

This communication was not described in detail until 1991, when Ferrari and Gilbert[6] classified it into four groups. We found the four-tiered classification of this branch useful because other studies presented only two variations. $[2,8,12,14,15]$ In our study, the Group 3 classification was found most frequently (43\%) as compared with the findings of Ferrari and Gilbert (30\%). The largest group described in the study of Ferrari and Gilbert was Group 1 with $44 \%$ of their hands classified in that category compared with $37 \%$ in our study. Group 2 classified hands were relatively equally distributed in both studies, 20\% in our study and $22 \%$ in the study by Ferrari and Gilbert. Group 4 hands were present only in Ferrari and Gilbert's study (4\%).

\section{Characteristics of the Communication}

This communication is a purely sensory branch whose distribution of innervation is the ulnar part of the middle finger and the radial part of the ring finger.[5,6,9,13,15,20,22] Injury to Berrettini's branch results in sensory alteration of a particular area not seen prior to the introduction of ECTR.[1,6,9,11,15]

\section{Clinical Implications}

It is our opinion that the Group 2 communication is the most at risk during ECTR because of its closeness to the distal margin of the TCL. A Group 1 communication may also be subject to injury because dissection is performed on the ulnar side of the TCL where the branch passes through. As a 
result of this study we recommend changing the course of the incision in the distal part of the carpal ligament from the ulnar side a few millimeters radially. The complications of sensory branch iatrogenic injury can be avoided by using this technical alteration.

\section{References}

1. Agee JM, Peimer CA, Pyrek JD, et al: Endoscopic carpal tunnel release: a prospective study of complications and surgical experience. J Hand Surg (Am) 20:165-171, 1995

2. Bonnel F, Vila RM: Anatomical study of the ulnar nerve in the hand. J Hand Surg (Br) 10:165-168, 1985

3. Dowdy PA, Richards RS, McFarlane RM: The palmar cutaneous branch of the median nerve and palmaris longus tendon: a cadaveric study. J Hand Surg (Am) 19:199-202, 1994

4. Eiken O, Carstam N, Eddeland A: Anomalous distal branching of the median nerve. Case reports. Scand J Plast Reconstr Surg 5:149-152, 1971

5. Engber WD, Gmeiner JG: Palmar cutaneous branch of the ulnar nerve. J Hand Surg (Am) 5:26-29, 1980

6. Ferrari GP, Gilbert A: The superficial anastomosis on the palm of the hand between the ulnar and median nerves. J Hand Surg (Br) 16:511-514, 1991

7. Franzini A, Broggi G, Servello D, et al: Transillumination in minimally invasive surgery for carpal tunnel release. Technical note. J Neurosurg 85:1184-1186, 1996

8. Hirasawa K: Plexus brachialis und die Nerven der oberen Extremität. Kyoto: Anatomischen Institutes der Kaiserlichen Universitat Kyoto, 1931

9. Lanz U: Anatomical variations of the median nerve in the carpal tunnel. J Hand Surg (Am) 2:44-53, 1977

10. Louis DS, Greene TL, Noellert RC: Complications of carpal tunnel surgery. J Neurosurg 62:352-356, 1985

11. MacDonald RI, Lichtman DM, Hanlon JJ, et al: Complications of surgical release for carpal tunnel syndrome. J Hand Surg (Am) 3:70-76, 1978

12. Mannerfelt L: Studies on the hand in ulnar nerve paralysis. A clinical-experimental investigation in normal and anomalous innervation. Acta Orthop Scand Supply 87:1-176, 1966

13. Mc Carthy RE, Nalebuff EA: Annomalous volar branch of the dorsal cutaneous ulnar nerve: case report. J Hand Surg (Am) 5:19-21, 1980

14. Meals RA, Calkins ER: Anomalous innervation of the upper extremity, in Gelberman RH (ed): Operative Nerve Repair and Reconstruction. Philadelphia: JB Lippincott, 1991, pp 197-204

15. Meals RA, Shaner M: Variations in digital sensory patterns: a study of the ulnar nerve - median nerve palmar communicating branch. J Hand Surg (Am) 8:411-414, 1983 
16. Papathanassiou BT: A variant of the motor branch of the median nerve in the hand. J Bone Joint Surg (Br) 50:156-157, 1968

17. Romano GP, Berrettini PC: Tabulae Anatomicae. Rome, 1741

18. Stanèic MF, Eskinja N, Stocic A: Anatomical variations of the median nerve in the carpal tunnel. Int Orthop 19:30-34, 1995

19. Sunderland S: Nerves and Nerve Injuries, ed 2. Edinburgh: Churchill-Livingstone, 1978

20. Taleisnik J: The palmar cutaneous branch of the median nerve and the approach to the carpal tunnel. An anatomical study. J Bone Joint Surg (Am) 55:1212-1217, 1973

21. Toldt C, Hochstetter F: Anatomische Atlas, ed 27. Munich: Urban \& Schwarzenberg, 1980

22. Tountas CP, Bihrle DM, MacDonald CJ, et al: Variations of the median nerve in the carpal canal. J Hand Surg (Am) 12:708-712, 1987

23. Williams PL, Warwick R, Dyson M, et al (eds): Gray's Anatomy, ed 37. Edinburgh: Churchill-Livingstone, 1989, pp 1133-1135

24. Wolf-Heidegger G: Atlas of Systematic Human Anatomy, ed 3. Basel: Karger, 1972

Manuscript received May 14, 1997.

Accepted in final form June 10, 1997.

Address reprint requests to: Marin F. Stancic, M.D., Gustava Krkleca 15, HR-51000 Rijeka, Croatia. email: marin.stancic@ ri.tel.hr. 